\title{
NANOCRYSTALLINE SILICON SUBSTITUTED HYDROXYAPATITE EFFECTS ON OSTEOCLAST DIFFERENTIATION AND RESORPTIVE ACTIVITY
}

\begin{tabular}{|r|l|}
\hline Journal: & Journal of Materials Chemistry B \\
\hline Manuscript ID: & TB-ART-11-2013-021697.R1 \\
\hline Article Type: & Paper \\
\hline Date Submitted by the Author: & n/a \\
\hline Complete List of Authors: & $\begin{array}{l}\text { Matesanz, Concepción; Universidad Complutense de Madrid, Bioquímica y } \\
\text { Biología Molecular I } \\
\text { Linares, Javier; Universidad Complutense de Madrid, Bioquímica y Biología } \\
\text { Molecular I } \\
\text { Lilue, Isabel; Universidad Complutense de Madrid, Bioquímica y Biología } \\
\text { Molecular I } \\
\text { Sánchez-Salcedo, Sandra; Universidad Complutense de Madrid, Inorgánica } \\
\text { yioinorgánica } \\
\text { Feito, María José; Universidad Complutense de Madrid, Bioquímica y } \\
\text { Biología Molecular I } \\
\text { Arcos, Daniel; Universidad Complutense de Madrid, Inorgánica y } \\
\text { Bioinorgánica } \\
\text { Vallet-Regi, Maria; Universidad Complutense de Madrid, Inorgánica y } \\
\text { Bioinorgánica } \\
\text { Portolés, María Teresa; Universidad Complutense de Madrid, Departamento } \\
\text { de Bioquímica }\end{array}$ \\
\hline
\end{tabular}




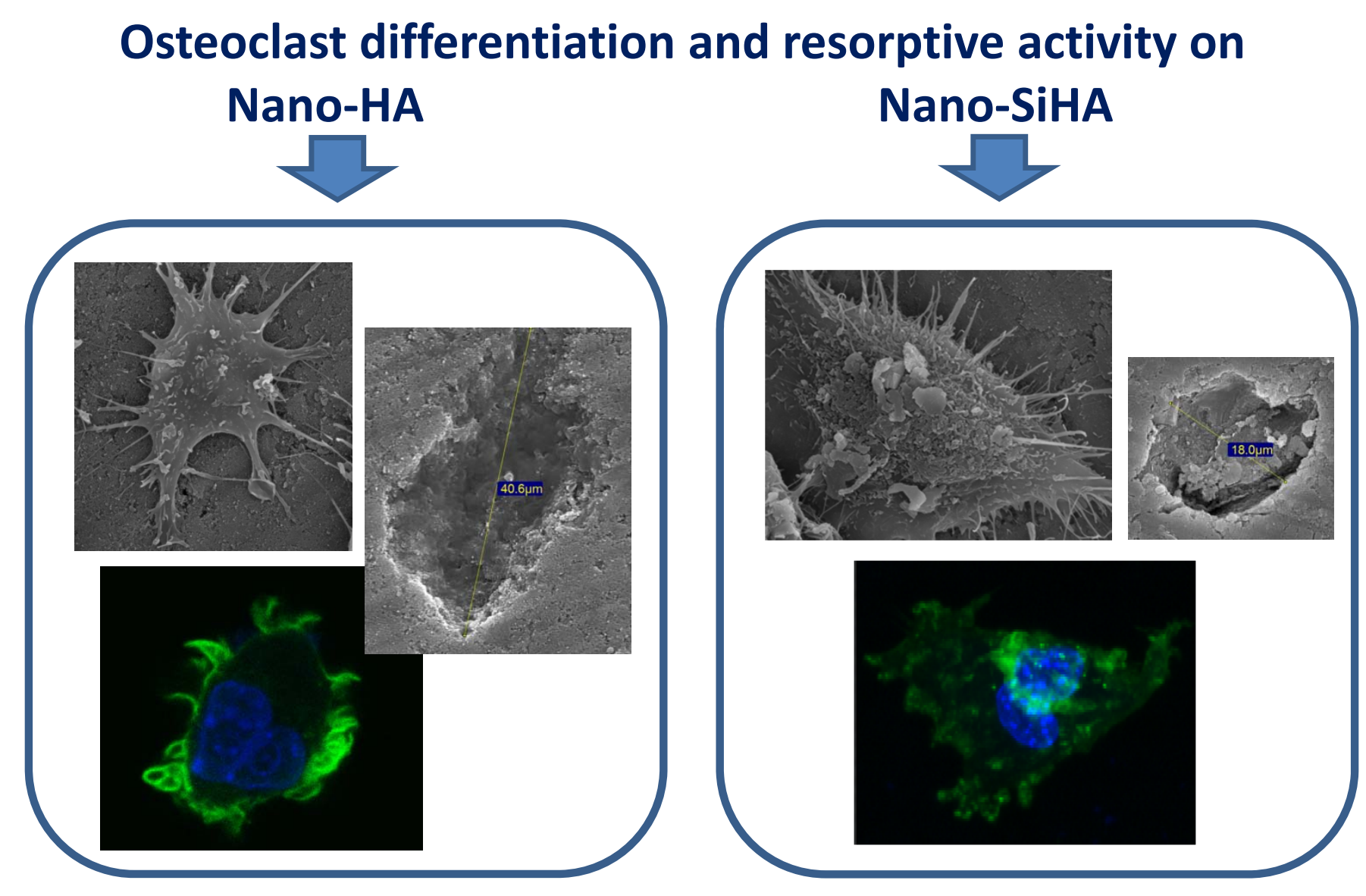




\section{Journal of Materials Chemistry B}

\section{ARTICLE}

Cite this: DOI:

\section{Nanocrystalline silicon substituted hydroxyapatite effects on osteoclast differentiation and resorptive activity}

Received

Accepted

DOI:

www.rsc.org/

\begin{abstract}
María Concepción Matesanz ${ }^{\mathrm{a}}$, Javier Linares ${ }^{\mathrm{a}, \mathrm{c}}$, Isabel Lilue ${ }^{\mathrm{a}}$, Sandra Sánchez-Salcedo ${ }^{\mathrm{b}, \mathrm{c}}$, María José Feito ${ }^{\mathrm{a}}$, Daniel Arcos ${ }^{\mathrm{b}, \mathrm{c}}$, María Vallet-Regí, ${ }^{\mathrm{b}, \mathrm{c}}$, María Teresa Portolés ${ }^{\mathrm{a}^{*}}$
\end{abstract}

In the present study, the effects of nanocrystalline hydroxyapatite (nano-HA) and nanocrystalline Si-substituted hydroxyapatite (nano-SiHA) on osteoclast differentiation and resorptive activity have been evaluated in vitro using osteoclast-like cells. The action of these materials on proinflammatory and reparative macrophage populations was also studied. NanoSiHA disks delayed the osteoclast differentiation and decreased the resorptive activity of these cells on their surface, as compared to nano-HA samples, without affecting cell viability. Powdered nano-SiHA also induced an increase of the reparative macrophage population. These results along with the beneficial effects on osteoblasts previously observed with powdered nano-SiHA suggest the potential of this biomaterial for modulating the fundamental processes of bone formation and turnover, preventing bone resorption and enhancing bone formation at implantation sites in treatment of osteoporotic bone and in bone repair and regeneration.

\section{Introduction}

Bone is a dynamic tissue in continuous remodelling which depends on resorption and new bone formation processes carried out by osteoclasts and osteoblasts respectively, working together in basic multicellular units. The main purpose of bone remodelling is to repair micro-fractures and maintain mineral homeostasis by providing access to stores of calcium and phosphate. ${ }^{1}$ Imbalances in bone turnover lead to bone loss and development of osteoporosis and ultimately fracture. Thus, osteoclasts, as principal bone-resorbing cells, are involved in the pathogenesis of various bone diseases, including osteoporosis. ${ }^{2,3}$ Severe bone loss due to excessive bone resorption is also observed in bacterial infection-related inflammatory diseases, such as periodontitis, osteomyelitis, and some types of arthritis. ${ }^{4}$ Osteoclasts are multinucleated giant cells which differentiate from hematopoietic stem cells (HSC) through different consecutive steps regulated by several growth factors and cytokines expressed by different cell types present at bone. ${ }^{5-7}$ HSC give rise to circulating mononuclear cells termed colony forming unit-granulocyte/macrophage (CFUGM) whose proliferation is stimulated by macrophage/ monocyte-colony forming factor (M-CSF), maintaining a pool of mononuclear cells in monocyte/macrophage lineage which are osteoclast precursors. ${ }^{8,9}$ These mononuclear precursors are attracted to the resorption sites, where they will then attach onto bone matrix to differentiate into prefusion osteoclasts with the stimulation of M-CSF and the receptor activator of nuclear factor kappa-B ligand (RANKL). RANKL is a protein found on the surface of the osteoblastic lineage cells, which may also be cleaved into a soluble form by metalloproteinases. RANKL interacts with its receptor, RANK, expressed on the surface of hematopoietic precursor cells thereby promoting osteoclast formation and maintaining their viability and activity. The continuous stimulation of M-CSF and RANKL induces the further differentiation of the prefusion osteoclasts which, by fusion, become multinucleated cells. The formation of "ruffled membrane", critical for bone resorption, is also stimulated by RANKL which promotes the survival of mature osteoclasts. ${ }^{8,10}$ Resorption implies an initial tight attachment of osteoclasts to the bone surface to create the "sealing zone", rich in F-actin. The osteoclast thus isolates the resorptive space from the surrounding bone. ${ }^{11,12}$ The ruffled border is formed by fusion of intracellular acidic vesicles which form finger-like projections inside the sealing zone. The vesicles contain a cocktail of matrix-degrading enzymes (such as cathepsin K), hydrogen ions $\left(\mathrm{H}^{+}\right)$and chloride ions $\left(\mathrm{Cl}^{-}\right)$which are released into the resorption lacunae and are responsible for acidification to a $\mathrm{pH}$ of around 4.5. ${ }^{13-15}$ This process produces the dissolution of the bone mineral component and enhances the enzymatic activity on the organic matrix. The degraded bone matrix is endocytosed from the resorption lacunae and transported by transcytotic carriers to the functional secretory domain, where it is released into the extracellular environment. ${ }^{16,17}$ Although these mechanisms of osteoclast action for bone resorption are well known, the bone remodelling process is not yet completely understood when osteoporosis is present. ${ }^{18}$ Pathological fractures are the natural consequence of osteoporosis and, for this reason, much attention has been given to fracture prevention through pharmacological and physical therapies. However, less attention has been directed at the study of orthopaedic biomaterials behaviour when implanted in 
osteoporotic bone. ${ }^{19}$ In fact, there are no clinically approved biomaterials specifically tailored for application in osteoporotic bones. Certainly, there are some examples of medical devices for osteosynthesis with special designs, but they are made of the same biomaterials than the conventional ones. ${ }^{19}$ Biomaterials that enhance the osteogenic function while decreasing the osteoclasts-mediated resorption, would be of great interest to fabricate implants specially tailored for osteoporotic patients. In this sense, nanocrystalline silicon substituted hydroxyapatites (nano-SiHA) could play a significant role for this biomedical purspose. In 1999, Gibson et al proposed SiHA as an improved bioceramic respect to stoichiometric hydroxyapatite. ${ }^{20}$ Thereafter, in vivo studies demonstrated that the bioactivity of HA was improved with the incorporation of $\mathrm{Si}^{21}$ This fact is explained in terms of a higher solution-mediated degradation of the apatite phase due to silicate presence within the crystalline structure, higher solubility at the grain boundary and an up-regulation in osteoblast cell metabolism in the early stages of bone formation. ${ }^{22-27}$. Since then, Si-substituted HAs have attracted the attention of many researchers and have recently been incorporated to the biomaterials market for spinal, orthopaedic, periodontal, oral and craniomaxillofacial applications. SiHA approved for clinical use are highly crystalline bioceramics treated at high temperatures. However, the possibility of enhancing bioceramics bioreactivity through their preparation as nanocrystalline compounds has been suggested. ${ }^{28,29}$ Higher surface area and smaller crystal size could thus provide very interesting bioresponses, especially in SiHA as the osteogenic effect of silicon is mainly explained by its location at the crystal boundaries. $^{22,23}$

In vitro cell cultures help to understand the interaction of bone remodeling cells with biomaterials. ${ }^{30}$ In the case of SiHA based bioceramics, the majority of in vitro studies are focused on the interaction of sintered and highly crystalline Si-HA with osteoblasts, ${ }^{31-33}$ and little is known about the interaction of highly crystalline SiHA with bone resorbing osteoclasts. ${ }^{34,35}$ The interaction of nanocrystalline SiHA with osteoblasts have been also studied by Thian et al. ${ }^{28,36}$ However, to the best of our knowledge, there are none study concerning osteoclast interactions with nanocrystalline SiHA. Since bone remodelling depends on resorption and new bone formation processes carried out by osteoclasts and osteoblasts respectively, in the present study we aimed to know the behaviour of osteoclasts on both nano-HA and nano-SiHA disks, evaluating their differentiation and resorptive activity in vitro. The results herein presented open new possibilities for tailoring biomaterials specially aimed to osteoporotic bone treatment.

On the other hand, cells with osteoclastogenic potential also exist in blood and peripheral hematopoietic organs and a common progenitor for osteoclasts, macrophages, and dendritic cells from murine bone marrow has been recently characterized. ${ }^{37}$ The capacity of macrophages to play both positive and negative roles in disease processes and tissue remodeling after injury, has been recently related to the balance between the proinflammatory (M1) and immunomodulatory /reparative (M2) macrophage phenotypes, with participation of diverse specific cytokines. ${ }^{38,39}$ Recent studies demonstrate the potential of biomaterials to modulate immune cell function, suggesting the possibility of designing biomaterials capable of eliciting appropriate immune responses at implantation sites. ${ }^{40}$
Previous studies have shown that Saos-2 osteoblasts grow better on nanocrystalline SiHA (nano-HA) disks than on nanocrystalline HA (nano-HA) disks. Since bone remodelling depends on resorption and new bone formation processes carried out by osteoclasts and osteoblasts respectively, in the present study we aimed to know the behaviour of osteoclasts on both nano-HA and nano-SiHA disks, evaluating their differentiation and resorptive activity in vitro. With this purpose, osteoclast-like cells have been differentiated for the first time on these substrates by treatment of RAW-264.7 macrophages with M-CSF and RANKL. The U0126 inhibitor of MAPKs (MEK) was used to potentiate the differentiation process.

\section{Materials and Methods}

\subsection{Nanocrystalline hydroxyapatite and silicon substituted hydroxyapatite synthesis}

Samples of pure and silicon substituted HA were prepared by aqueous precipitation reaction of $\mathrm{Ca}\left(\mathrm{NO}_{3}\right)_{2} \cdot 4 \mathrm{H}_{2} \mathrm{O}$, $\left(\mathrm{NH}_{4}\right)_{2} \mathrm{HPO}_{4}$ and tetraethyl orthosilicate $\mathrm{Si}\left(\mathrm{CH}_{3} \mathrm{CH}_{2} \mathrm{O}\right)_{4}$ (TEOS) solutions. The amounts of reactants were calculated on the assumption that phosphorus would be substituted by silicon. Two different compositions have been prepared with nominal formula $\mathrm{Ca}_{10}\left(\mathrm{PO}_{4}\right)_{6-\mathrm{x}}\left(\mathrm{SiO}_{4}\right)_{\mathrm{x}}(\mathrm{OH})_{2-\mathrm{x}}$, with $\mathrm{x}=0$ and 0.25 for nano-HA and nano-SiHA samples, respectively, as previously reported by Arcos et al. ${ }^{26}$ Briefly, $1 \mathrm{M} \mathrm{Ca}\left(\mathrm{NO}_{3}\right)_{2} \cdot 4 \mathrm{H}_{2} \mathrm{O}$ solution was added to $\left(\mathrm{NH}_{4}\right)_{2} \mathrm{HPO}_{4}$ and TEOS solutions of stoichiometric concentration to obtain the compositions described above. The mixture was stirred for 12 hours at $80^{\circ} \mathrm{C}$. During the reaction the $\mathrm{pH}$ was continuously adjusted to 9.5 to ensure constant conditions during the synthesis. The asprecipitated powders were milled, sieved and treated at $700^{\circ} \mathrm{C}$ for 2 hours under air atmosphere to remove the nitrates without introducing important changes in the crystallite size respect to the as precipitated powder. The HA and Si-HA particles thus obtained have a diameter ranging in size between 10 to 100 micrometers, whereas the averaged crystallite sizes are $30 \mathrm{~nm}$ and $24 \mathrm{~nm}$ for nano-HA and nano-SiHA, respectively, as previously reported. ${ }^{26}$

\subsection{Preparation of nano-HA and nano-SiHA disks}

Fractions of $300 \mathrm{mg}$ of the as-precipitated powders of HA and Si-HA materials were milled, sieved and pressed into diskshape $(11 \mathrm{~mm}$ diameter, $2 \mathrm{~mm}$ height) by means of 3 tons of uniaxial pressing. Thereafter the disks were treated at $700^{\circ} \mathrm{C}$ for two hours under air atmosphere.

\subsection{Culture of RAW-264.7macrophages and treatment with nano-HA or nano-SiHA}

RAW-264.7 cells were seeded on 6 well culture plates (CULTEK S.L.U., Madrid, Spain) at a density of $10^{5}$ cells $/ \mathrm{ml}$ in Dulbecco's Modified Eagle Medium (DMEM) supplemented with $10 \%$ fetal bovine serum (FBS, Gibco, BRL), $1 \mathrm{mM} \mathrm{L}$ glutamine (BioWhittaker Europe, Belgium), penicillin (200 $\mu \mathrm{g} / \mathrm{ml}$, BioWhittaker Europe, Belgium), and streptomycin (200 $\mu \mathrm{g} / \mathrm{ml}$, BioWhittaker Europe, Belgium), under a $\mathrm{CO}_{2}(5 \%)$ atmosphere at $37^{\circ} \mathrm{C}$ for $24 \mathrm{~h}$. Then, $1 \mathrm{mg} / \mathrm{ml}$ of either nano-HA or nano-SiHA were added to cultured RAW-264.7 and maintained under a $\mathrm{CO}_{2}(5 \%)$ atmosphere at $37^{\circ} \mathrm{C}$ for $24 \mathrm{~h}$. 
Parallel controls were carried out in the absence of material. After this treatment, the attached cells were washed with PBS and harvested using cell scrapers. Then, $10 \mu \mathrm{l}$ of the cell suspensions were counted with a Neubauer hemocytometer for the analysis of cell proliferation and cell suspensions were centrifuged at $310 \mathrm{xg}$ for $10 \mathrm{~min}$ and resuspended in fresh medium for analysis of different parameters by Flow Cytometry as described below ( 2.6 section).

\subsection{Osteoclast differentiation on nano-HA and nano-SiHA} disks.

Murine RAW-264.7 macrophages were seeded on either nano-HA or nano-SiHA disks, previously introduced into 24 well culture (CULTEK S.L.U., Madrid, Spain), at a density of $2 \times 10^{4}$ cells $/ \mathrm{ml}$ in Dulbecco's Modified Eagle Medium (DMEM) supplemented with $10 \%$ fetal bovine serum (FBS, Gibco, BRL), $1 \mathrm{mM}$ L-glutamine (BioWhittaker Europe, Belgium), penicillin $(200 \mu \mathrm{g} / \mathrm{ml}$, BioWhittaker Europe, Belgium), and streptomycin $(200 \mu \mathrm{g} / \mathrm{ml}$, BioWhittaker Europe, Belgium). In order to stimulate osteoclast differentiation, $40 \mathrm{ng} / \mathrm{ml}$ of mouse RANK Ligand recombinant protein (TRANCE/RANKL, carrier-free, BioLegend, San Diego), $25 \mathrm{ng} / \mathrm{ml}$ recombinant human macrophage-colony stimulating factor (M-CSF, Milipore, Temecula) and U0126 (5 $\mu \mathrm{M}$ Promega, Madison, WI, USA) were added to the culture medium. Cells were cultured under a $\mathrm{CO}_{2}(5 \%)$ atmosphere and at $37^{\circ} \mathrm{C}$ for 21 days, renewing culture medium every 5-7 days. After 21 days culture on nano-HA and nano-SiHA disks, cells were washed with PBS, harvested using PBS-EDTA during $10 \mathrm{~min}$ and counted with a Neubauer hemocytometer. Cell suspensions were then centrifuged at $310 \mathrm{xg}$ for $10 \mathrm{~min}$ and resuspended in fresh medium for the analysis of different parameters by flow cytometry as described below ( 2.5 section).

\subsection{Flow Cytometry studies}

After incubation with the different probes, as is described below, the conditions for the data acquisition and analysis were established using negative and posit

ive controls with the CellQuest Program of Becton Dickinson. These conditions were maintained during all the experiments. At least 10,000 cells were analyzed in each sample.

\subsubsection{Cell cycle analysis and apoptosis detection}

Cell suspensions were incubated with Hoechst 33258 (PolySciences, Inc., Warrington, PA) (Hoechst $5 \mu \mathrm{g} / \mathrm{ml}$, ethanol $30 \%$, and BSA $1 \%$ in PBS), used as a nucleic acid stain, during $30 \mathrm{~min}$ at room temperature in darkness. The fluorescence of Hoechst was excited at $350 \mathrm{~nm}$ and the emitted fluorescence was measured at $450 \mathrm{~nm}$ in a LSR Becton Dickinson Flow Cytometer. The cell percentage in each cycle phase: G0/G1, S and $\mathrm{G} 2 / \mathrm{M}$ was calculated with the CellQuest Program of Becton Dickinson and the SubG1 fraction was used as indicative of apoptosis.

\subsubsection{Intracellular reactive oxygen species (ROS) content and cell viability}

Cells were incubated at $37^{\circ} \mathrm{C}$ for 30 min with $100 \mu \mathrm{M} \mathrm{2}, 7^{\prime}-$ dichlorofluorescein diacetate (DCFH/DA, Serva, Heidelberg/ Germany) for directly measuring the intracellular content of ROS. DCFH/DA is diffused into cells and is deacetylated by cellular esterases to non-fluorescent DCFH, which is rapidly oxidized to highly fluorescent DCF by ROS. To measure the intracellular reactive oxygen species (ROS), the DCF fluorescence was excited by a $15 \mathrm{~mW}$ laser tuning to 488 $\mathrm{nm}$ and the emitted fluorescence was measured with a 530/30 band pass filter in a FACScalibur Becton Dickinson Flow Cytometer. Cell viability was determined by propidium iodide (PI) exclusion test and flow cytometry after addition of PI $(0.005 \%$ in PBS, Sigma-Aldrich Corporation, St. Louis, MO, USA) to stain the DNA of dead cells.

\subsubsection{Intracellular calcium content}

Cell suspensions were incubated with the probe Indo-1 AM at a concentration of $10 \mu \mathrm{M}$ for $30 \mathrm{~min}$ at room temperature, in darkness and with shaking. The fluorescence of Indo-1 was excited at $325 \mathrm{~nm}$ and the emitted fluorescence was measured with $380 \mathrm{~nm}$ long pass (FL1) and 424/44 $\mathrm{nm}$ band pass (FL2) filters in a LSR Becton Dickinson flow cytometer. After all the measurements, $10 \mu \mathrm{M}$ A-23187 ionophore (Enzo Life Sciences) was added in order to test the sensitivity of the assay.

\subsection{Morphological studies by Confocal Microscopy}

Cells cultured on nano-HA and nano-SiHA disks were fixed with $3.7 \%$ paraformaldehyde in PBS for $10 \mathrm{~min}$, washed with PBS and permeabilizated with $0.1 \%$ Triton X-100 for 3 to 5 min. The samples were then washed with PBS and preincubated with PBS containing 1\% BSA for 20 to $30 \mathrm{~min}$. Then cells were incubated during $20 \mathrm{~min}$ with FITC phalloidin (Dilution 1:40, Molecular Probes) to stain F-actin filaments. Samples were then washed with PBS and the cell nuclei were stained with DAPI (4'-6-diamidino-2'-phenylindole, $3 \mu \mathrm{M}$ in PBS, Molecular Probes). After staining and washing with PBS, cells were examined by a LEICA SP2 Confocal Laser Scanning Microscope. The fluorescence of FITC was excited at $488 \mathrm{~nm}$ and the emitted fluorescence was measured at 491-586 nm. DAPI fluorescence was excited at $405 \mathrm{~nm}$ and measured at $420-480 \mathrm{~nm}$.

\subsection{Morphological Studies by Scanning Electron Microscopy}

Scanning electron macroscopy and EDX spectroscopy was carried out with a JEOL JSM-6400 scanning electron microscope. Since gold coating overlap with phosphorous signal in the EDX analysis, Nano-HA and Nano-SiHA disks were coated with graphite.

Cells cultured on nano-HA and nano-SiHA disks were fixed with glutaraldehyde $(2.5 \%$ in PBS) for $45 \mathrm{~min}$. Sample dehydration was performed by slow water replacement using series of ethanol solutions $(30,50,70,90 \%)$ for $15 \mathrm{~min}$ with a final dehydration in absolute ethanol for $30 \mathrm{~min}$, allowing samples to dry at room temperature and under vacuum. Afterwards, the pieces were mounted on stubs and coated in vacuum with gold-palladium.

\subsection{Observation of osteoclast resorption cavities by Scanning Electron Microscopy}

To observe the geometry of resorption cavities produced by osteoclasts on the surface of nano-HA and nano-SiHA disks, cells were detached after 21 days culture on these biomaterials and disks were dehydrated, coated with gold-palladium (as in 
2.8 section) and examined with a JEOL JSM-6400 scanning electron microscope.

\subsection{Inflammatory cytokine detection}

The amounts of TNF- $\alpha$ and IL- 6 in the culture medium were quantified by ELISA (Gen-Probe, Diaclone), carried out according to the manufacturer's instructions.

\subsection{Statistics}

Data are expressed as means + standard deviations of one representative experiment out of three experiments carried out in triplicate. Statistical analysis was performed using the Statistical Package for the Social Sciences (SPSS) version 19 software. Statistical comparisons were made by analysis of variance (ANOVA). Scheffé test was used for post hocevaluations of differences among groups. In all of the statistical evaluations, $\mathrm{p}<0.05$ was considered as statistically significant.

\section{Results and discussion}

Bone remodelling depends on the balance between osteoblastic bone formation and osteoclastic bone resorption. Differentiation and activity of both osteoblasts and osteoclasts are precisely regulated processes and can greatly be influenced by the presence of a biomaterial. ${ }^{1}$ Thus, silicate nanoparticles have been recently used in an animal model to stimulate bone growth by inhibiting osteoclasts while enhancing the activity of osteoblasts. ${ }^{41}$ However, little is known about the effects on osteoclast differentiation/activity produced by the majority of biomaterials designed for bone tissue. Silicon substituted hydroxyapatites (Si-HA) are among the most interesting calcium phosphates for bone repair with comparable biocompatibility and mechanical properties to hydroxyapatite (HA) but improved bioactivity which enhances bone tissue growth rate. ${ }^{22-24,36,42}$ The beneficial actions of Si-substituted calcium phosphates have been recently revised, but the majority of studies concerning the $\mathrm{Si}$ effects have focused on bone formation and osteoblasts. ${ }^{31-33,43-47}$ In the present study, taking into account that osteoclasts derive from a monocyte/ macrophage precursor, ${ }^{37}$ the in vitro effects of nanocrystalline hydroxyapatite (nano-HA) and nanocrystalline silicon substituted hydroxyapatite (nano-SiHA) on murine RAW-264.7 macrophages were analyzed, as was the capacity of these cells to differentiate into mature osteoclasts on the surface of these biomaterials in the presence of soluble RANKL and M-CSF in the culture medium.

Figures 1A and 1B depict the scanning electron micrographs obtained disks of nano-HA and nano-SiHA, respectively. Both surfaces show large and irregular particles ranging in size between 10 and 50 micrometers. These particles do not show the typical polyhedral morphology of highly crystalline ceramics treated at high temperature. On the contrary, they exhibit irregular shapes with incomplete sintered grain boundaries, as would correspond to pressed powders treated at temperatures below the sintering point.

Figures 1C and 1D show the EDX spectra for nano-HA and nano-SiHA, which agree with the chemical compositions expected for the nominal formulas $\mathrm{Ca}_{10}\left(\mathrm{PO}_{4}\right)_{6}(\mathrm{OH})_{2}$ and $\mathrm{Ca}_{10}\left(\mathrm{PO}_{4}\right)_{5.7}\left(\mathrm{SiO}_{4}\right)_{0.3}(\mathrm{OH})_{1.7}$.

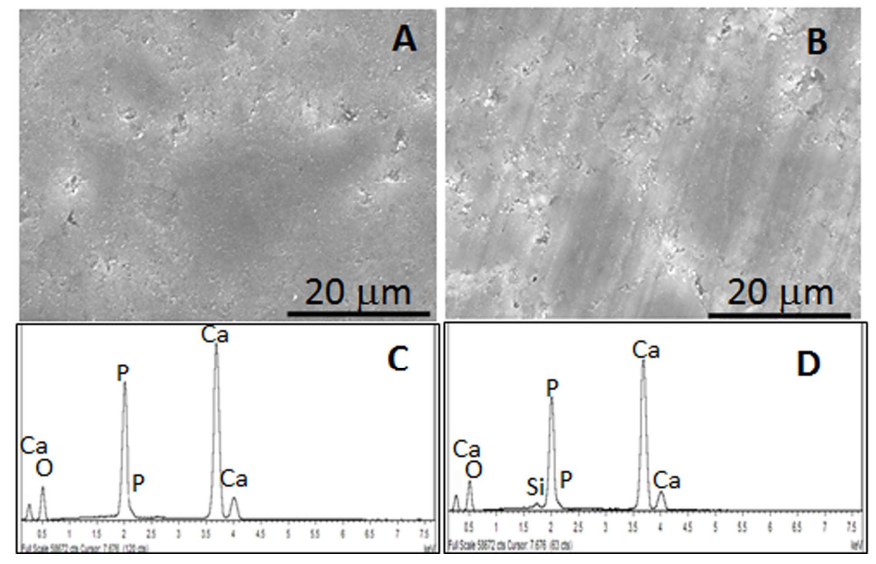

Fig. 1 Scanning electron micrographs (magnification x 2000) obtained from disks of nano-HA (A) and nano-SiHA (B). EDX spectra corresponding to nano-HA (1C) and nano-SIHA (1D), respectively.
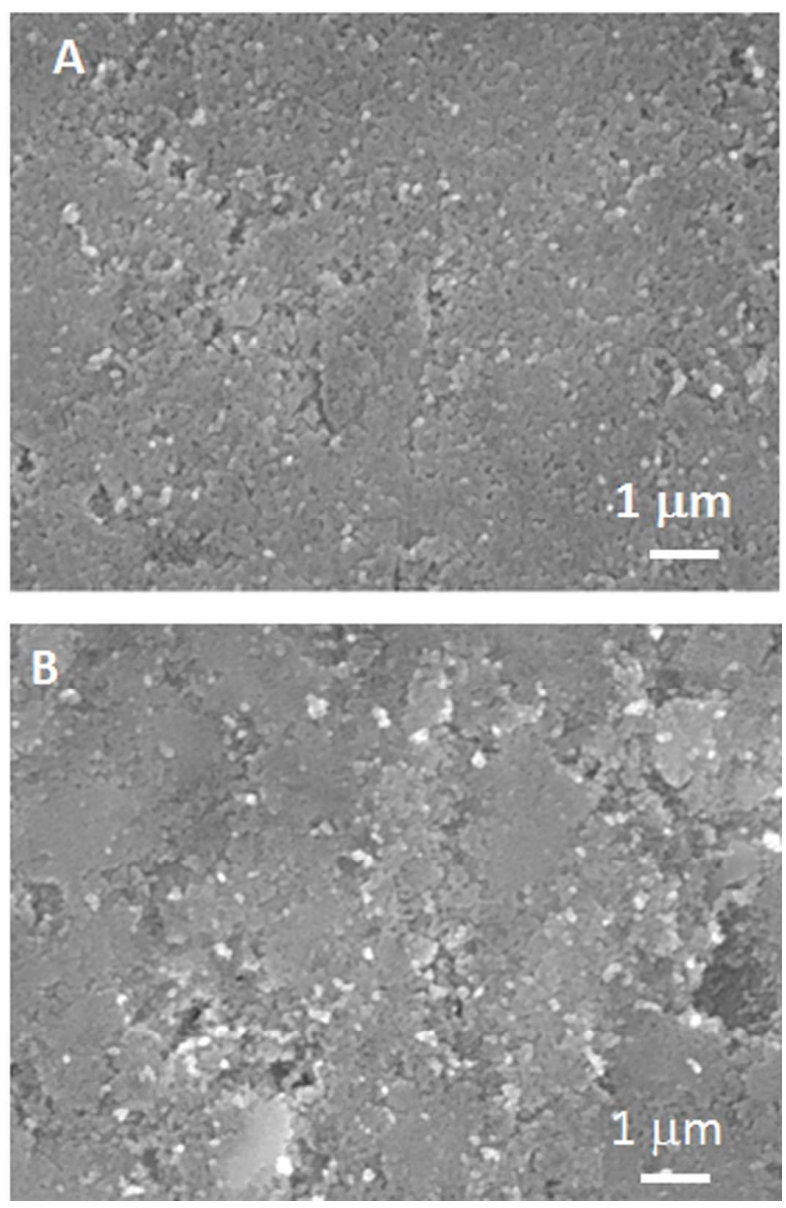

Fig. 2 Scanning electron micrographs (magnification x 10000) obtained from disks of nano-HA (A) and nano-SiHA (B)

SEM observations of the surfaces at higher magnifications (Figure 2) show that the large grains are formed by nanoparticles leaving porosity at the nanoescale. This is due to the low thermal treatment, which is clearly insufficient to lead the crystal growth of the as-precipitated nanocrystalline powders. The micrographs also evidence the presence of 
macropores (larger than $50 \mathrm{~nm}$ ) and surface defects that, from a qualitative point view, seem to be more numerous in nanoSiHA (Figure 2B).

Figure 3A shows macrophage proliferation values after 1 day culture with either nano-HA or nano-SiHA $(1 \mathrm{mg} / \mathrm{ml}$ in powder form). As can be observed, both materials produced a significant decrease of RAW-264.7 cell proliferation in comparison with controls in the absence of material. This effect has been previously observed using cultured L929 fibroblasts, Saos-2 osteoblasts and MC3T3-E1 preosteoblasts. ${ }^{24,48}$
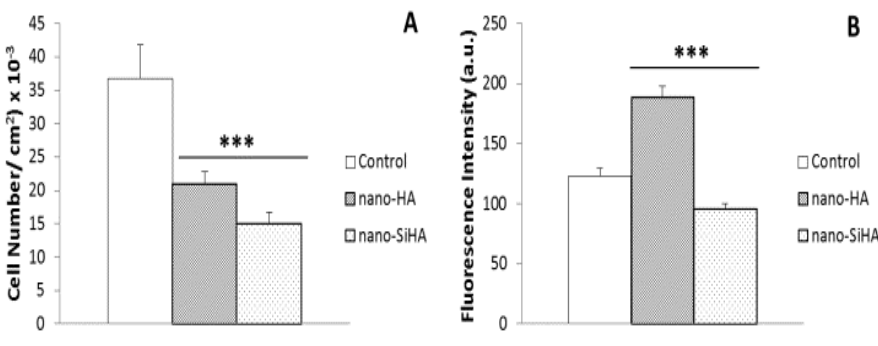

Fig. 3 Effect of $1 \mathrm{mg} / \mathrm{ml}$ of powdered nano-HA and nano-SiHA on proliferation (A) and intracellular ROS content (B) of RAW-264.7 macrophages after 1 day treatment. Controls without material were carried out in parallel. $* * * \mathrm{p}<0.005$.

Increased reactive oxygen species (ROS) formation has been described in response of macrophages to different hydroxyapatite dispersions. ${ }^{49}$ When the intracellular ROS content of RAW-264.7 macrophages was evaluated by flow cytometry with the probe DCFH/DA, after 1 day treatment with either nano-HA or nano-SiHA, a significant increase induced by nano-HA was observed at this short time of culture. However, macrophages treated with nano-SiHA showed lower ROS values than control (Figure 3B), thus indicating a beneficial action of Si-substituted material in agreement with other studies. $^{22-24,36,42,43}$

To know the possible effects of these biomaterials on macrophage phenotypes, the analysis of two RAW-264.7 cell populations, with high and low intracellular ROS content, was carried out in the samples by flow cytometry after DCFH labelling. As can be observed in Figure 4, the percentage of low ROS population is significantly higher in control and nanoSiHA samples than in nano-HA treated cells, whereas the high ROS population is significantly higher in nano-HA compared with nano-SiHA and control. The two populations observed, can be related to the proinflammatory (M1, high ROS) and reparative (M2, low ROS) macrophage phenotypes, whose balance has been involved in the macrophage capacity to play both negative and positive roles in disease processes and tissue remodelling after injury. ${ }^{38,39}$ Although further studies are necessary to establish the effects of these nanocrystalline hydroxyapatites on macrophage polarization, the results obtained suggest the beneficial role of nano-SiHA which could favour the reparative population with low ROS content. In this sense, recent studies suggest the potential of biomaterials to modulate immune response at implantation sites. ${ }^{40}$

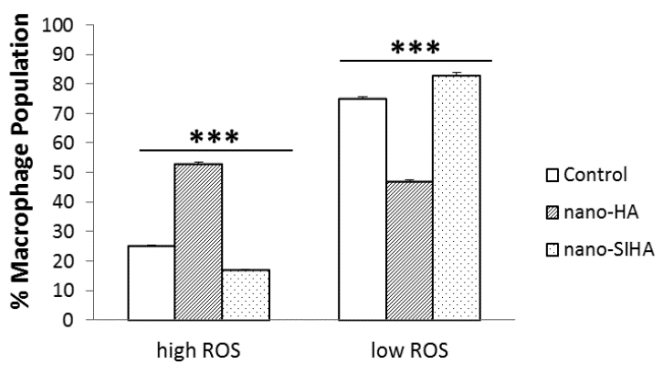

Fig. 4 Effect of $1 \mathrm{mg} / \mathrm{ml}$ of powdered nano-HA and nano-SiHA on RAW-264.7 macrophage populations concerning intracellular ROS content after 1 day treatment. Controls without material were carried out in parallel. $* * * \mathrm{p}<0.005$.

In order to evaluate the action of nano-HA and nano-SiHA on osteoclast differentiation and resorptive activity in vitro, osteoclasts were differentiated by treatment of RAW-264.7 macrophages with M-CSF and RANKL on the surface of disks prepared with these biomaterials. The U0126 inhibitor of MAPKs (MEK) was used to potentiate the differentiation process. ${ }^{50}$ As can be observed in Figures 5 and 6, continuous stimulation with these factors induces osteoclast-like cell differentiation on both materials by fusion of macrophagic precursors leading to multinucleated cells (asterisks indicate the nuclei in the insets of Fig. 5A and 5B, and in Fig. 6D). The formation of long and numerous finger-like projections (podosomes) was also observed (thin arrows in Fig. 5C and 5D and Fig. 6), as well as the F-actin ring which allows creation of the "sealing zone" (thick arrows in Fig. 5B and 6C), which is critical for bone resorption.
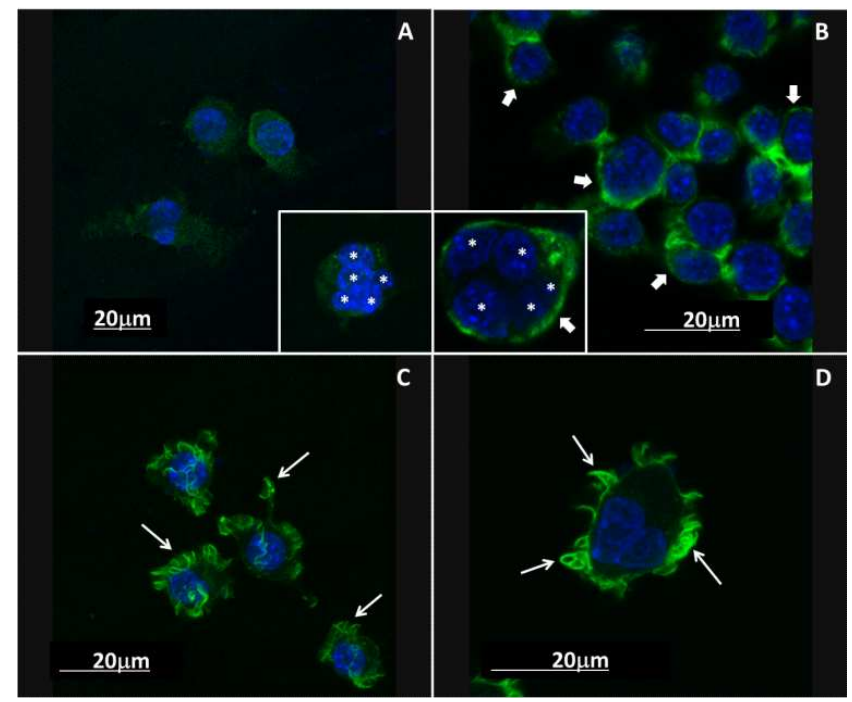

Fig. 5 Morphology evaluation by Confocal Microscopy of osteoclastlike cells cultured on nano-HA disks, stained with DAPI (for the visualization of the cell nuclei) and FITC phalloidin (for the visualization of cytoplasmic F-actin filaments). Asterisks indicate the nuclei, thin arrows the podosomes and thick arrows the F-actin ring of the "sealing zone". 


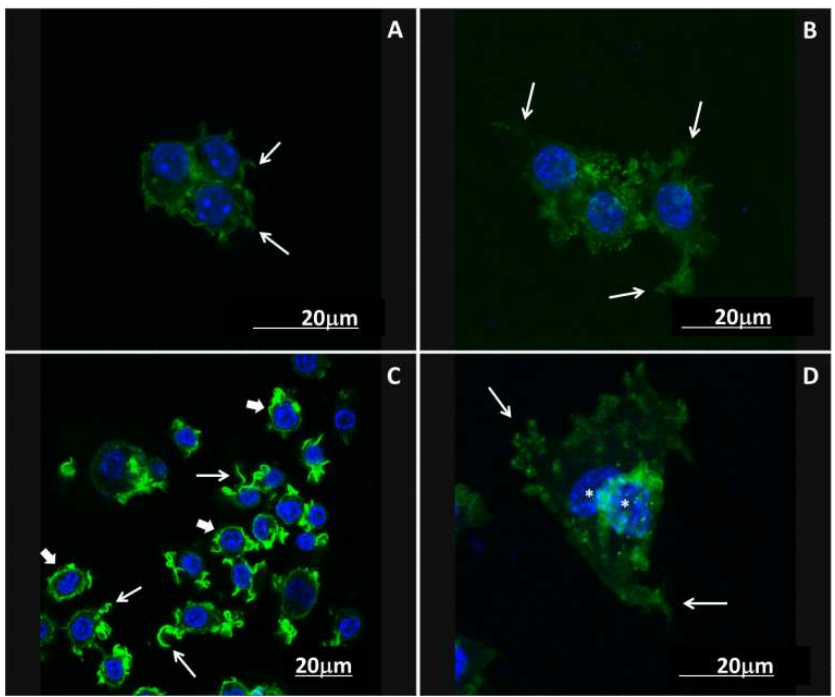

Fig. 6 Morphology evaluation by Confocal Microscopy of osteoclastlike cells cultured on nano-SiHA disks, stained with DAPI (for the visualization of the cell nuclei) and FITC phalloidin (for the visualization of cytoplasmic F-actin filaments). Asterisks indicate the nuclei, thin arrows the podosomes and thick arrows the F-actin ring of the "sealing zone".

All these morphological characteristics reveal the osteoclastogenesis on these nanocristallyne hydroxyapatites in agreement with other studies carried out with carbonatesubstituted hydroxyapatite. ${ }^{51}$ However, some differences were observed between osteoclast-like cells differentiated on nanoHA and nano-SiHA disks. A higher number of nuclei per cell was observed on nano-HA surface (asterisks in the insets of Fig. 5A and 5B) than on nano-SiHA disks (asterisks in Fig. 6D). The statistical analysis of the multinucleated cells showed $10 \%$ of multinucleated cells on both materials. However, in contact with nano-SiHA, these multinucleated cells contain two nuclei and the multinucleated cells on nano-HA disks contain four or five nuclei. Although the formation of F-actin ring and podosomes, related to the definition of the sealing zone, was observed on both materials, more organized podosomes were evident in the cells differentiated on nano-HA (thin arrows in Fig. 5C and 5D) than on nano-SiHA (thin arrows in Fig. 6C). All these results reveal that nano-SiHA produces a delay in the osteoclastogenesis probably due to the presence of $\mathrm{Si}$. In this sense, experiments with RAW-264.7 macrophages demonstrate that $\mathrm{Si}$ affects the late stages of differentiation and fusion of osteoclasts, causing a significant inhibition of osteoclast phenotypic gene expressions, osteoclast formation and bone resorption in vitro. 52

Figure 7 shows the proliferation (A) and cell viability (B) of osteoclast-like cells differentiated on nano-HA and nanoSiHA disks. As it can be observed in Figure 7A, the cell growth on nano-SiHA surface was significantly lower than on nano-HA disks after 21 days. However, high viability values on both biomaterials (up $80 \%$ ) were obtained (Fig. 7B). The significant decrease of osteoclast proliferation produced by nano-SiHA, probably due to the presence of $\mathrm{Si}$, is in agreement with the powdered nano-SiHA action on RAW-264.7 cells (Fig. 3A), and can be related to the same origin of both cell types from a monocyte/macrophage precursor. ${ }^{37}$ Previous results have shown a significant $\mathrm{Ca}^{2+}$ decrease in the culture medium produced by both nano-HA and nano-SiHA, more pronounced with nano-SiHA, in agreement with the higher bioactivity of this material. ${ }^{42,53}$ The observed sequestration of extracellular calcium can be partially responsible of the lower proliferation of osteoclasts on nano-SiHA observed in the present study. Recently, it has been observed that bioglass 45S5 particles cause a significant reduction of osteoclast-like cells in both the marrow cultures and RAW-264.7 cells, suggesting a direct inhibitory effect of $\mathrm{Si}$ on the osteoclast precursors that is not due to cell toxicity. ${ }^{52}$ However, previous studies with Saos-2 osteoblasts showed that the number of Saos-2 cells after 4 days culture in contact with nano-SiHA was significantly higher than with nano-HA, indicating that this cell type grows better in the presence of nano-SiHA. This result was also observed by Scanning Electron Microscopy (SEM) when Saos-2 osteoblasts were cultured for 4 days on surface of both nano-HA and nanoSiHA disks. SEM images demonstrated that Saos- 2 cells adhere to the nano-SiHA disk, proliferate and colonize its surface better than on nano-HA disk. ${ }^{24}$ Previous studies also showed that osteoblasts cultured on nano-SiHA surface showed the typical bone cell morphology, cube-shape, and big sized, joining other cells to construct a net through strong cellular union. $^{24}$ Adhesion and proliferation processes are good indicators of the cell response that could be expected when a biomaterial is used in vivo. Thus, the previous results obtained with osteoblasts cultured on nano-SiHA disks indicates a good biocompatibility and an adequate interaction of osteoblasts with nano-SiHA material.
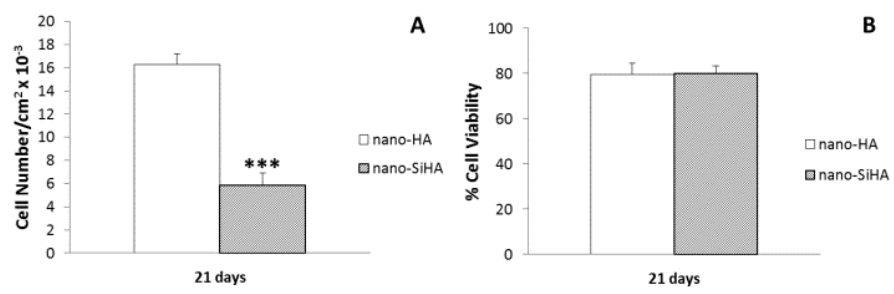

Fig. 7 Proliferation (A) and cell viability (B) of osteoclast-like cells cultured on nano-HA and nano-SiHA disks. ${ }^{* * *} \mathrm{p}<0.005$.

Since proliferation is dependent on the cell cycle progression, in which cells pass through the $G_{0} / G_{1}$ phase (Quiescence/Gap 1) to the $\mathrm{S}$ phase (Synthesis) and finally to the $\mathrm{G}_{2} / \mathrm{M}$ phase (Gap 2 and Mitosis), the cell cycle phases of osteoclast-like cells cultured on nano-HA disks and nano-SiHA disks were analysed. No significant changes were observed (Figure 8), demonstrating that these materials do not produce toxicity on osteoclast-like cells, in agreement with the results obtained from the propidium iodide exclusion test (Figure 7B). The analysis of SubG1 fraction, corresponding to cells with fragmented DNA, reveals low apoptosis levels induced by both materials (Figure 8) but slightly higher on nano-SiHA than on nano-HA (Figure 9A).

Intracellular ROS and $\mathrm{Ca}^{2+}$ play essential roles for osteoclastogenesis. ${ }^{54}$ Thus, following stimulation with RANKL, the pre-osteoclasts increase intracellular ROS by activation of NADPH oxidase (Nox) homologs or by increased mitochondria ROS production, which subsequently induced long lasting $\mathrm{Ca}^{2+}$ oscillations. ${ }^{54-56}$ In the present study both intracellular ROS and $\mathrm{Ca}^{2+}$ content of osteoclast-like cells cultured on nano-HA disks and nano-SiHA disks were analyzed by Flow Cytometry and higher values of both parameters were obtained in cells cultured on nano-SiHA than on nano-HA (Fig. 9B and 9C). These results could suggest the existence of a differentiation delay produced by nano-SiHA on RAW-264.7 cells, in agreement 
with the morphological characteristics observed by Confocal Microscopy (Fig. 5 and 6).
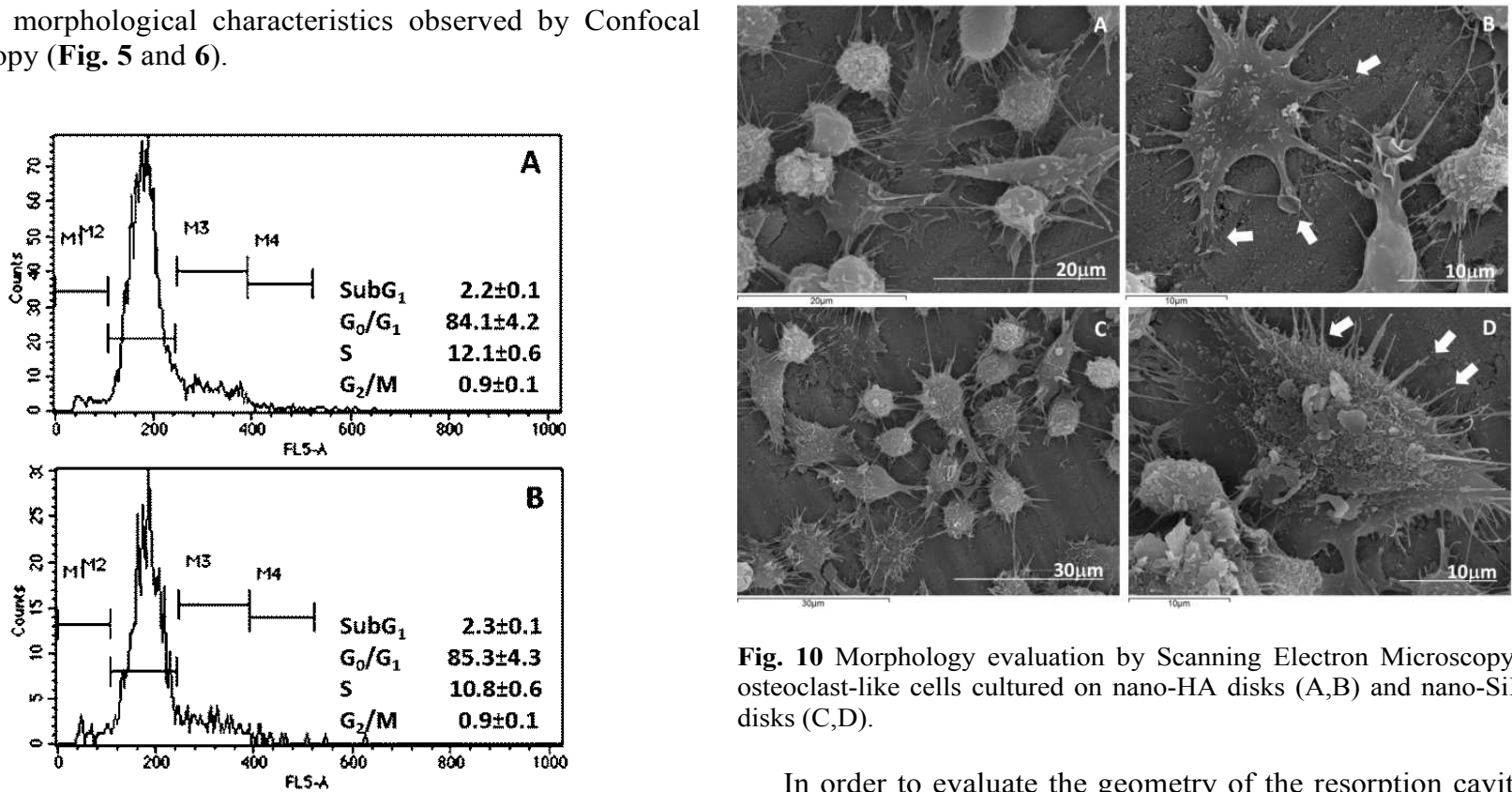

Fig. 10 Morphology evaluation by Scanning Electron Microscopy of osteoclast-like cells cultured on nano-HA disks $(\mathrm{A}, \mathrm{B})$ and nano-SiHA disks (C,D).

In order to evaluate the geometry of the resorption cavities

Fig. 8 Effect on cell cycle phases of osteoclast-like cells cultured on nano-HA disks (A) and nano-SiHA disks (B).

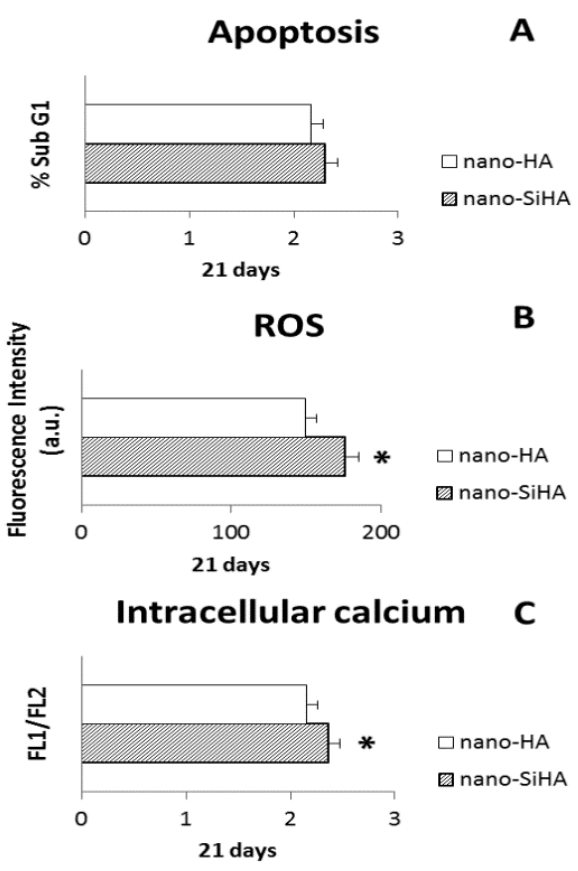

Fig. 9 Effect on apoptosis (A), ROS production (B) and cytosolic $\mathrm{Ca}^{2+}$ (C) of osteoclast-like cells cultured on nano-HA and nano-SiHA disks. $* p<0.05$.

Figure 10 shows by Scanning Electron Microscopy (SEM) the morphology of RAW-264.7 macrophages differentiated into osteoclast-like cells cultured on nano-HA disks (Fig. 10A and 10B) and nano-SiHA disks (Fig. 10C and 10D). These SEM studies demonstrate the presence of cells attached on both surfaces, presenting typical characteristics of osteoclasts with many longer podosomes.

left by osteoclast-like cells cultured on nano-HA and nanoSiHA samples, the surfaces of these materials were analyzed by SEM after cell detachment. As can be observed in Figure 11, osteoclasts cultured on nano-HA disks demonstrate higher resorptive activity (Fig. 11A and 11B) than on nano-SiHA disks (Fig. 11C and 11D) after 21 days culture in the presence of RANKL, M-CSF and U0126. Resorption cavities on nanoHA surface present higher size than on nano-SiHA surface which shows spherical cavities (inset in Figure 11D). The statistical analysis of the cave size showed values of $10 \pm 1.7$ $\mu \mathrm{m}$ on nano-SiHA and $32.5 \pm 9.7 \mu \mathrm{m}$ on nano-HA $(* * \mathrm{p}<0.01)$. Concerning the resorption of nanocrystalline calcium phosphates by osteoclast-like cells, Detsch et al. have recently showed that nano-HA with low carbonate content strongly stimulated the differentiation and resorption of these cells on its surface when compared with carbonate-rich samples. ${ }^{12}$
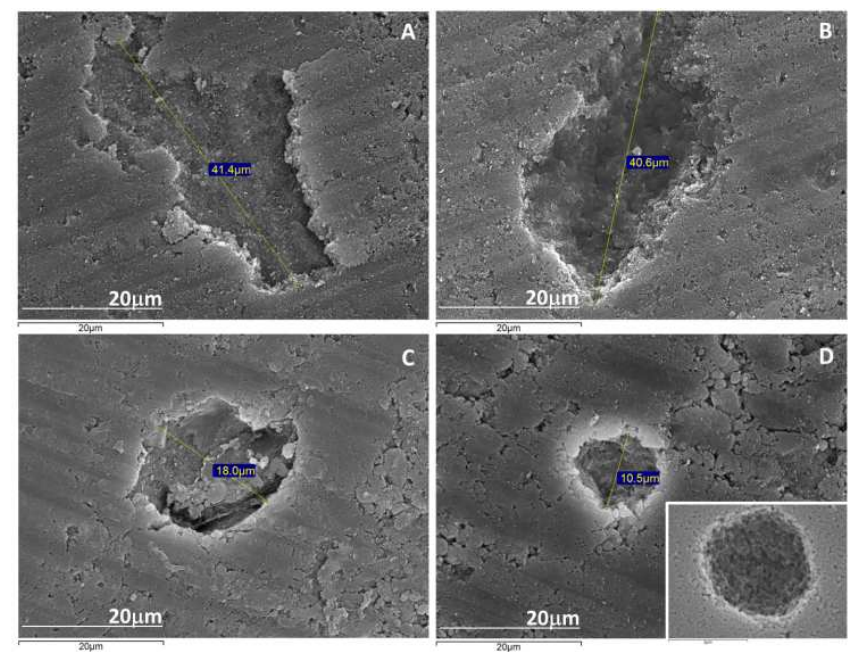

Fig. 11 Morphology evaluation by Scanning Electron Microscopy of the resorption cavities left by osteoclast-like cells cultured on nano-HA disks (A, B) and nano-SiHA disks (C,D). 
Resorption implies an initial tight attachment of osteoclasts to the disk surface to create the "sealing zone", rich in F-actin, which isolates the resorptive space from the surrounding material. ${ }^{11,12}$ The ruffled border is formed by fusion of intracellular acidic vesicles which contain enzymes (such as cathepsin $\mathrm{K}$ ), $\mathrm{Cl}^{-}$and $\mathrm{H}^{+}$ions which are released into the resorption lacunae for the acidification to a $\mathrm{pH}$ of around 4.5 . $^{13-}$ ${ }^{15}$ This process produces the dissolution of the material, which is then endocytosed from the resorption cavity and transported to the secretory domain for releasing into the extracellular environment. ${ }^{16,17}$

Many different stimuli have been shown to regulate $\mathrm{Ca}^{2+}$ concentrations in osteoclasts and extracellular acidification has been described as causing a decrease in intracellular $\mathrm{Ca}^{2+}$ concentration in isolated chicken osteoclasts. ${ }^{57}$ The lower $\mathrm{Ca}^{2+}$ content observed in the present study with osteoclast-like cells cultured on nano-HA disks in comparison to cells cultured on nano-SiHA samples (Figure 9C) can be related to higher extracellular acidification produced by these cells on nano-HA surface than on nano-SiHA surface, as demonstrated by the geometry of the resorption cavities observed on this material (Fig. 11A and 11B).

Since it has been found that osteoclast differentiation is induced by tumor necrosis factor (TNF)- $\alpha$ and IL- $6,{ }^{58,59}$ these cytokines were evaluated in the culture medium of RAW-264.7 macrophages at different times during the differentiation into osteoclast-like cells on nano-HA disks and nano-SiHA disks. As can be observed, both TNF- $\alpha$ (Figure 12A) and IL-6 (Figure 12B) levels increased progressively in the culture medium during osteoclast differentiation. The values of both cytokines were always significantly higher in the presence of nano-SiHA than nano-HA.

Taking into account that TNF- $\alpha$ and IL-6 modulate osteoclastogenesis, the increase of these cytokines in the presence of nano-SiHA could be explained by a higher secretion as a response to stimulate the differentiation process which is delayed on this material. However, in mouse bone marrow-derived macrophages (BMMs), IL-6 decreased osteoclast formation and bone-resorption ability. ${ }^{60}$ Taking into account the results obtained with BMMs, the nano-SiHA effects on osteoclastogenesis and resorption activity observed in the present study, also could be caused by an increase of IL- 6 induced by this material (Figure 12B). Other cytokines as TNF- $\alpha$ and IL-1 $\beta$, showed various responses according to the phase of osteoclast maturation and the concentration of each cytokine and RANKL. ${ }^{60}$
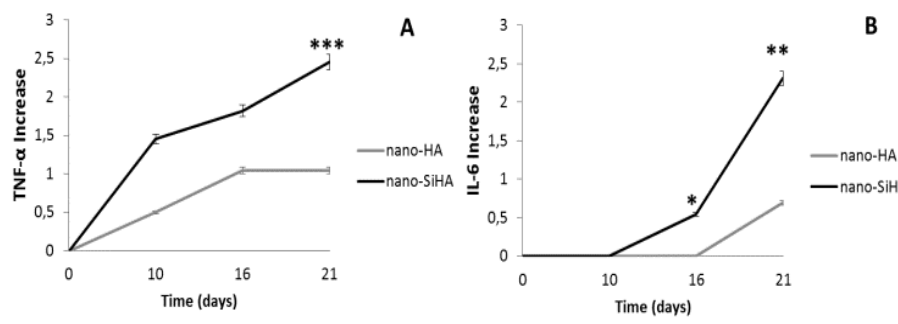

Fig. 12 Effects on TNF- $\alpha$ (A) and IL-6 (B) release to culture medium of osteoclast-like cells cultured on nano-HA and nano-SiHA disks. $* \mathrm{p}<0.05, * * \mathrm{p}<0.01, * * * \mathrm{p}<0.005$.

\section{Conclusions}

Since bone is a dynamic tissue in continuous remodelling which depends on resorption and new bone formation processes carried out by osteoclasts and osteoblasts respectively, in the present study we aimed to know the behaviour of osteoclasts on both nano-HA and nano-SiHA disks, evaluating for the first time the differentiation and the substrate resorption carried out by this cell type on both substrates. This study demonstrates that nanocrystalline Si-substituted hydroxyapatite delays the osteoclast differentiation and decreases the resorptive activity of these cells on their surface, as compared to nanocrystalline hydroxyapatite, without affecting cell viability. Furthermore, the demonstrated increase of the reparative macrophage population, along with the beneficial effects on osteoblasts previously observed with powdered nano-SiHA, suggest the potential of this biomaterial for modulating the fundamental processes of bone formation and turnover, preventing bone resorption and enhancing bone formation at implantation sites in treatment of osteoporotic bone and in bone repair and regeneration.

\section{Acknowledgements}

This study was supported by research grants from Comunidad de Madrid through the project S2009/MAT-1472 and the Ministerio de Ciencia e Innovacion (MICINN) through the projects MAT2012-35556 and CSO2010-11384-E (Agening Network of Excellence). M.C. Matesanz and J. Linares are greatly indebted to MICINN and CIBER-BBN respectively for predoctoral fellowships. The authors wish to also thank the staff of the Cytometry and Fluorescence Microscopy Centre of the Universidad Complutense de Madrid (Spain) and ICTS National Centre for Electron Microscopy (Spain).

\section{Notes and references}

a Department of Biochemistry and Molecular Biology I, Faculty of Chemistry, UCM, 28040-Madrid, Spain

${ }^{b}$ Department of Inorganic and Bioinorganic Chemistry, Faculty of Pharmacy, UCM, Instituto de Investigación Sanitaria Hospital 12 de Octubre i+12, 28040-Madrid, Spain

$c$ Networking Research Center on Bioengineering, Biomaterials and Nanomedicine, CIBER-BBN, Spain

* Corresponding author: E-mail address: portoles@quim.ucm.es

1 P. Pivonka, J. Zimak, D. W. Smith, B. S. Gardiner, C. R. Dunstan, N. A. Sims, T. J. Martin, G. Mundy. Bone 2008, 43, 249-263.

2 S.C. Manolagas. Aging 1998, 10, 182-190.

3 T. Luhmann, O. Germershaus, J. Groll, L. Meinel. J. Control. Release 2012, 161, 198-213.

4 S. P. Nair, S. Meghji, M. Wilson, K. Reddi, P. White, B. Henderson. Infect. Immun. 1996, 64, 2371-2380.

5 X. Feng. Gene 2005, 350, 1-13.

6 H. K. Väänänen, T. Laitala-Leinonen. Arch. Biochem. Biophys. 2008, 473,132-138. 
7 G. J. Atkins, D. R. Haynes, S. M. Geary, M. Loric, T. N. Crotti, D. M. Findlay DM. Bone 2000, 26, 653-661.

8 T. Suda, N. Takahashi, N. Udagawa, E. Jimi, M. T. Gillespie, T. J. Martin. Endocr. Rev. 1999, 20, 345-357.

9 S. L. Teitelbaum, M. M. Tondravi, F. P. Ross. J. Leukoc. Biol. 1997, 61, 381-388.

10 S. Wang, W. S. El-Deiry. Oncogene 2003, 22, 8628-8633.

11 J. E. Aubin. J. Bone Miner. Res. 1992, 7, 365-368.

12 R. Detsch, D. Hagmeyer, M. Neumann, S. Schaefer, A. Vortkamp, M. Wuelling, G. Ziegler, M. T. Epple. Acta Biomater. 2010, 6, 32233233.

13 A. Qin, T. S. Cheng, N. J. Pavlos, Z. Lin, K. R. Dai, M. H. Zheng. Int. J. Biochem. Cell. Biol. 2012, 44, 1422-1435.

14 H. K. Väänänen, Y. K. Liu, P. Lehenkari, T. Uemara. Mater. Sci. Eng. C 1998, 6, 205-209.

15 H. C. Blair, S. L. Teitelbaum, R. Ghiselli, S. Gluck. Science 1989, 245, 855-857.

16 H. C. Blair, N. A. Athanasou. Histol. Histopathol. 2004, 19, 189-199.

17 S. L. Teitelbaum. Science 2000, 289, 1504-1508.

18 H. Namkung-Matthai, R. Appleyard, J. Jansen, H. Lin, S. Maastricht, M. Swain, R. S. Mason, G. A. Murrell, A. D. Diwan, T. Diamond. Bone 2001, 28, 80-86.

19. D. Arcos, A. R. Boccaccini, M. Bohner, A. Díez-Pérez, M. Epple, E. Gómez-Barrena, A. Herrera, J. A. Planell, L. Rodríguez-Mañas, M. Vallet-Regí. Acta Biomaterialia (2014) DOI 10.1016/j.actbio.2014.01.004.

20 I.R. Gibson, S.M. Best, W. Bonfield. J Biomed. Mater. Res. 1999, 44, 422-

21 N. Patel, S.M. Best, W. Bonfield, I.R. Gibson, K.A. Hing, E. Damien, P.A. Revell. J. Mater Sci Mater Med 2002, 13, 1199-1206.

22 M. Vallet-Regí, D. Arcos. J. Mater. Chem. 2005, 15, 1509-1516.

23 A. E. Porter, N. Patel, J. N. Skepper, S. M. Best, W. Bonfield. Biomaterials 2003, 24, 4609-4620.

24 M. C. Matesanz, M. J. Feito, C. Ramírez-Santillán, R. M. Lozano, S. Sánchez-Salcedo, D. Arcos, M. Vallet-Regí, M. T. Portolés. Macromol. Biosci. 2012, 12, 446-453.

25 A. Balamurugan, A. H. Rebelo, A. F. Lemos, J. H. Rocha, J. M. Ventura, J. M. Ferreira. Dent. Mater. 2008, 24, 1374-1380.

26 D. Arcos, J. Rodríguez-Carvajal, M. Vallet-Regí. Chem. Mater. 2004, 16, 2300-2308.

27 E. M. Carlisle. Calcif. Tissue Int. 1981, 33, 27-34.

28 E.S. Thian Z. Ahmad J. Huang M.J. Edirisinghe S.N. Jayasinghe D.C. Ireland R.A. Brooks N. Rushton W. Bonfield S.M. Best. Acta Biomaterialia 2010, 6, 750-755

29 S. V. Dorozhkin. Materials 2009, 2, 1975-2045.

30 M. Fini, G. Giavaresi, P. Torricelli, V. Borsaria, R. Giardino, A. Nicolini, A. Carpi. Biomed. Pharmacother. 2004, 58, 487-493.

31 C.M. Botelho, R.A. Brooks, S.M. Best, M.A. Lopes, J.D. Santos, N. Rushton, W. Bonfield. J Biomed Mater Res A, 2006, 79A, 723-730.

32 H Marques da Silva, M. Mateescu, C. Damia, E. Champion, G.Soares, K. Anselme. Coll Surf B Biointerfaces 2010, 80, 138-144

33 M Honda, K. Kikushima, Y. Kawanobe, T. Konishi, M. Mizumoo, M. Aizawa. J Mater Sci Mater Med 2012, 23, 2923-2932

34 C.M. Botelho, R.A. Brooks, G. Spence, I. McFarlane, M.A. Lopes, S.M. Best, J.D. Santos, N. Rushton, W. Bonfield. J Biomed Mater Res $A, 2006,78$ A, 709-720.
35 G. Lehmann, I. Cacciotti, P. Palmero, L. Montanaro, A. Bianco, L. Campagnolo, A. Camaioni Biomed Mater 2012, 7, 055001

36 E. S. Thian, J. Huang, S. M. Best, Z. H. Barber, R. A. Brooks, N. Rushton, W. Bonfield. Biomaterials, 2006, 27, 2692-2698.

37 C. E. Jacome-Galarza, S. K. Lee, J. A. Lorenzo, H. L. Aguila. J. Bone Miner. Res. 2013, 28, 1203-1213.

38 B. N. Brown, B. D. Ratner, S. B. Goodman, S. Amar, S. F. Badylak. Biomaterials 2012, 33, 3792-3802.

39 P. M. Kou, J. E. Babensee. J. Biomed. Mat. Res. A 2011, 96, 239-260.

40 S. Franz, S. Rammelt, D. Scharnweber, J. C. Simon. Biomaterials 2011, 32, 6692-6709.

41 G. R. Beck, S. W. Ha, C. E. Camalier, M. Yamaguchi, Y. Li, J. K. Lee, M. N. Weitzman. Nanomed. Nanotech. Biol. Med. 2012, 8, 793803.

42 A. M. Pietak, J. M. Reid, M. J. Stott, M. Sayer. Biomaterials 2007, 28, 4023-4032.

43 M. Bohner. Biomaterials 2009, 30, 6403-6406.

44 O. Tsigkou, J. R. Jones, J. M. Polak, M. M. Stevens. Biomaterials 2009, 30, 3542-3550.

45 D. M. Reffitt, N. Ogston, R. Jugdaohsingh, H. F. Cheung, B. A. Evans, R. P. Thompson, J. J. Powell, G. N. Hampson. Bone 2003, 32, 127-135.

46 M. Wiens, X. Wang, H. C. Schroder, U. Kolb, U. Schlossmacher, H. Ushijima, W. E. Müller. Biomaterials 2010, 31, 7716-7725.

47 S. Zou, D. Ireland, R. A. Brooks, N. Rushton, S. Best. J. Biomed. Mater. Res. B Appl. Biomater. 2009, 90, 123-130.

48 M. J. Feito, R. M. Lozano, M. Alcaide, C. Ramírez-Santillán, D. Arcos, M. Vallet-Regí, M. T. Portolés. J. Mater. Sci. Mater. Med. 2011, 22, 405-416.

49 C. Albrecht, A. M. Scherbart, D. van Berlo, C. M. Braunbarth, R. P. Schins, J. Scheel. Toxicol. In Vitro 2009, 23, 520530.

50 H. Hotokezaka, E. Sakai, K. Kanaoka, K. Saito, K. Matsuo, H. Kitaura, N. Yoshida. J. Biol. Chem. 2002, 277, 47366-47372.

51 G. Spence, N. Patel, R. Brooks, N. Rushton. J. Biomed. Mater. Res. A 2009, 90, 217-224.

52 Z. Mladenović, A. Johansson, B. Willman, K. Shahabi, E. Björn, M. Ransjö M. Acta Biomaterialia 2014, 10, 406-418.

53 M.C. Matesanz, M. J. Feito, M. Oñaderra, C. Ramírez-Santillán, C. da Cas, D. Arcos, M. Vallet-Regí, J. M. Rojo, M. T. Portolés. J. Colloid Interface Sci. 2014, 416, 59-66

54 M. S. Kim, Y. M. Yang, A. Son, Y. S. Tian, S. I. Lee, S. W. Kang, S. Muallem, D. M. Shin. J. Biol. Chem. 2010, 285, 6913-6921.

55 X. He, G. Andersson, U. Lindgren, Y. Li. Biochem. Biophys. Res. Commun. 2010, 401, 356-362.

56 S. Srinivasan, A. Koenigstein, J. Joseph, L. Sun, B. Kalyanaraman, M. Zaidi, N. G. Avadhani. Ann. N. Y. Acad. Sci. 2010, 1192, 245252.

57 S. Y. Hwang, J. W. Putney Jr. Biochim. Biophys. Acta 2011, 1813, 979-983.

58 H. Kitaura, N. Nagata, Y. Fujimura, H. Hotokezaka, M. Tatamiya, N. Nakao, N. Yoshida, K. Nakayama. Immunol. Lett. 2003, 88, 193-198.

59 N. Rozen, S. Ish-Shalom, A. Rachmiel, H. Stein, D. Lewinson. Bone 2000, 26, 469-474.

60 S. Moon, I. E. Ahn, H. Jung, H. Yi, J. Kim, Y. Kim, S. K. Kwok, K. S. Park, J. K. Min, S. H. Park, H. Y. Kim, J. H. Ju. Int. J. Mol. Med. 2013, 31, 769-777. 
Dear Editor:

Concerning our revised manuscript entitled "NANOCRYSTALLINE SILICON SUBSTITUTED HYDROXYAPATITE EFFECTS ON OSTEOCLAST DIFFERENTIATION AND RESORPTIVE ACTIVITY" (Manuscript ID TB-ART-11-2013-021697), we have taken the Reviewers' comments into account and I am glad to send you the revised version of the manuscript which includes all the changes made highlighted. The authors thank the comments of the reviewers aimed to improve the quality of our manuscript. A detailed list of these changes and the responses to the Reviewers' comments is included below.

Referee: 1

Comments to the Author

In this manuscript, Matesanz and coworkers investigated the effects of nanocrystalline silicon substituted hydroxyapatite (Nano-SiHA) on the differentiation and resorptive activity of human osteoclast cells. By the experimental data, they concluded that the Nano-SiHA can delay the osteoclast differentiation and decreased the resorptive activity of cells on substrates. This manuscript was well-written and well-organized, but it is clear that the novelty and significance are not enough for the publication on JMCB (see previous reports like: Biomaterials, 2006, 27, 2692; J Biomed Mater Res A, 2006, 78A, 709; J Biomed Mater Res A, 2006, 79A, 723) and some of the conclusions are needed to further consider and proved. Therefore, this manuscript is not recommended for publication at presented version, but it may be considered after a major revision and resubmission.

\section{Authors}

After considering the reviewer's comments regarding the lack of novelty and significance of our manuscript, the authors think that we failed in explaining these aspects in the first version. We hope that this revised version will satisfy the standards of JMCB. Anyway, we want to clarify herein the novelty and significance of our work. After the article of Gibson et al (J Biomed. Mater Res 1999, 44, 422), the interest for these bioceramics has continuously increased during the last 15 years. Regarding cell culture studies, there are numerous articles dealing with the interaction of sintered and highly crystalline Si-HA with osteoblasts (for instance the article suggested by the reviewer Botelho et al. J Biomed Mater Res $A, 2006,79 A, 723)$ and a few ones considering osteoclasts, specifically Botelho et al. $J$ Biomed Mater Res A, 2006, 78A, 709 and Lehmann et al Biomed Mater 2012, 7, 055001. The interaction of nanocrystalline Si-HA with bone cells have been also studied by Thian et al. Biomaterials, 2006, 27, 2692 (as the reviewer pointed out), but that work was carried out with osteoblasts. To the best of our knowledge, our manuscript is the first study about the interaction of nanocrystalline Si-HA with osteoclasts.

In order to determine the role of the silicon within nanocrystalline $H A$ on the osteoclasts behaviour, we have compared our compounds with pure nano HA. The results 
indicate that nano-SiHA disks delayed the osteoclast differentiation and decreased the resorptive activity of these cells on their surface, as compared to nano-HA samples, without affecting cell viability. These results along with the beneficial effects on osteoblasts previously observed with powdered nano-SiHA suggest the potential of this biomaterial for bone repairing specially in osteoporotic patients. This finding is of great significance, since there are no clinically approved biomaterials specifically tailored for application in osteoporotic bones. Certainly, there are some examples of medical devices for osteosynthesis with special designs, but they are made of the same biomaterials than the conventional ones (D. Arcos et al, The relevance of biomaterials to the prevention and treatment of osteoporosis. Opinion paper, Acta Biomaterialia (2014) DOI 10.1016/j.actbio.2014.01.004.)

We hope that this answer will change the reviewer's mind respect to the degree of novelty and significance of our manuscript. The authors thank the comments and the references pointed by the reviewer, insofar they have helped to improve the discussion of this work.

\section{Referee 1.}

1. In the "introduction" part, it is suggested that the authors should put more attentions on the biomedical application of Nano-SiHA, and provide more information on the previous studies on cell culture on Nano-SiHA and Nano-HA substrates.

\section{Authors}

The authors agree with the reviewer's comment. The potential application nano-SiHA for bone tissue repairing in osteoporotic patients is highlighted in the revised version. In an osteoporotic scenario, the paucity of bone and the decreased osteoblasts function result in an impaired response to implants compared with healthy bones. The osteointegration in these cases is seriously affected, mainly due to the decreased osteoblast activity. An osteoporotic environment strongly affects the primary (short-term) stability of the implant, because the quality of the host bone is significantly decreased. Moreover, biological stability (early and long-term) is also impaired, as it requires deposition of newly formed bone in intimate contact with the implant. Since this process involves the balanced action of osteogenic and bone resorbing cells, osteoporosis often has a poor prognosis and delayed healing and osteointegration with endosseous implants. Nano-SiHA presented in this work, indicates capability to enhance osteoblastic function while delaying the osteoclast mediated bone resorption. For this reason, the authors strongly believe that nano-SIHA is a very interesting biomaterial addressed to treat bone defects in osteoporotic patients.

In this new version, more attention has been paid to previous studies with nano SiHA and nano HA. New references, including those proposed by the reviewer, have been added.

2. In addition, in the "Introduction" part, the authors should point out the novelties and significances of their work. What are the improvements compared to previous studies? It is unclear in the present version. 


\section{Authors}

As mentioned above, the authors think that we failed in explaining these aspects in the first version. The novelties and significances respect to previous works have been highlighted in this new version.

3. In the previous studies of the osteoblast differentiation on Nano-SiHA substrate (for example, Biomaterials, 2006, 27, 2692), researchers found that the growth of cells on NanoSiHA can be significantly enhanced. But in this manuscript, the authors concluded that the Nano-SiHA delayed the cell differentiation and decreased the resorptive activity of cells on surface. What are the differences between the cell experiments of osteoblast and osteoclast? Why the authors used the osteoclast cells in this study? More information should be provided.

\section{Authors}

Concerning the previous studies on cell culture on both nanocrystalline materials, when Saos-2 osteoblasts were cultured for $4 d$ on surface of both nano-HA and nano-SiHA disks, Scanning Electron Microscopy images demonstrated that Saos-2 cells adhere to the SiHA disks, proliferate and colonize their surface better than on HA disks (reference 28). Previous studies also showed that osteoblasts cultured on nano-SiHA surface showed the typical bone cell morphology, cube-shape, and big sized, joining other cells to construct a net through strong cellular union (reference 28). Adhesion and proliferation processes are good indicators of the cell response that could be expected when a biomaterial is used in vivo. Thus, our previous results obtained with osteoblasts cultured on nano-SiHA disks indicates a good biocompatibility and an adequate interaction of osteoblasts with nano-SiHA material. In the present study we used osteoclasts because bone is a dynamic tissue in continuous remodelling which depends on resorption and new bone formation processes carried out by osteoclasts and osteoblasts respectively. Thus, in the present study our objective was to know the behaviour of osteoclasts cultured on both nano-HA and nano-SiHA disks, evaluating for the first time the differentiation and the substrate resorption carried out by this cell type on both substrates. Concerning the resorption of nanocrystalline calcium phosphates by osteoclast-like cells, Detsch et al. have recently showed that nano-HA with low carbonate content strongly stimulated the differentiation and resorption of these cells on its surface when compared with carbonate-rich samples [Reference 12]. These data and more comments on our previous results with human Saos-2 osteoblasts have been included in the revised version of the manuscript (in the Introduction, Results/discussion and Conclusions sections) in order to provide more information and to highlight the novelties and significances of our work, as suggested by the reviewer.

4. In Figure 3 and 4 , the captions for the figures are not clear.

\section{Authors}

More information is now provided in the captions of Figures 3 and 4 in order to clarify the confocal images explaining that asterisks indicate the nuclei in the insets, thin arrows indicate the podosomes and thick arrows the F-actin ring which allows creation of the "sealing zone" for bone resorption. 
5. In Figure 5, it is clear that the cell growth at the beginning on Nano-SiHA substrate is clearly slower than that on Nano-HA, but at the long period it on the same level. What is the reason? More explanation should be given.

\section{Authors}

Figure 5 (fig 7 in revised version) shows the proliferation (A) and cell viability (B) of RAW-264.7 macrophages differentiated into osteoclast-like cells cultured on nano-HA and nano-SiHA disks after 21 days. As it can be observed in Figure 5A, the cell growth of osteoclast-like cells on nano-SiHA surface was significantly lower than on nano-HA surface after 21 days. The values presented in Figure 5B correspond to viability values which are on the same level but this Figure 5B does not correspond to cell growth at a longer period. These explanations have been improved in the revised version of the manuscript.

6. For the conclusion for Figure 8, the authors indicated that "cells attached on ....obtained by confocal microscopy". It is clear that there is no difference of cells between the Nano-SiHA and Nano-HA substrates. The authors indicated "shorter and thicker" of cells on Nano-HA, but this situation can be also found for the cells on Nano-SiHA substrate. Therefore, the conclusion is not supported by the data.

\section{Authors}

Since the Scanning Electron Microscopy images do not show clear differences between the podosomes of the cells attached on nano-HA and nano-SiHA, the conclusion for Figure 8 (fig 10 in the revised version) has been eliminated in the revised manuscript, as suggested by the reviewers 1 and 2.

7. In Figure 9, the authors provided the SEM images of substrates after recorption of cells. It is seemed that these images can reveal nothing, because there is only one resorption cave. Images with more caves should be presented. In addition, a statistical analysis of the cave size is needed.

\section{Authors}

The SEM images in figure 9 (fig 11 in revised version) correspond certainly to caves produced by the resorptive activity of osteoclasts cultured on nano-HA and nano-SiHA disks because the size of these caves are in the size range of cells and because these caves were not observed on disks without cells. The two images which are included below correspond to nano-HA and nano-SiHA disks without cells and these samples did not show caves with size similar to cell size. These two images have not included in the revised manuscript to avoid an excess of figures. As suggested by the reviewer, we have considered more caves to carry out the statistical analysis of the cave size obtaining values of $10 \pm 1.7 \mu \mathrm{m}$ (on nano-SiHA) and $32.5 \pm 9.7 \mu \mathrm{m}$ (on nano-HA). The statistical significance of these values was $* * p<0.01$. These data have been included in the text of the revised manuscript. 

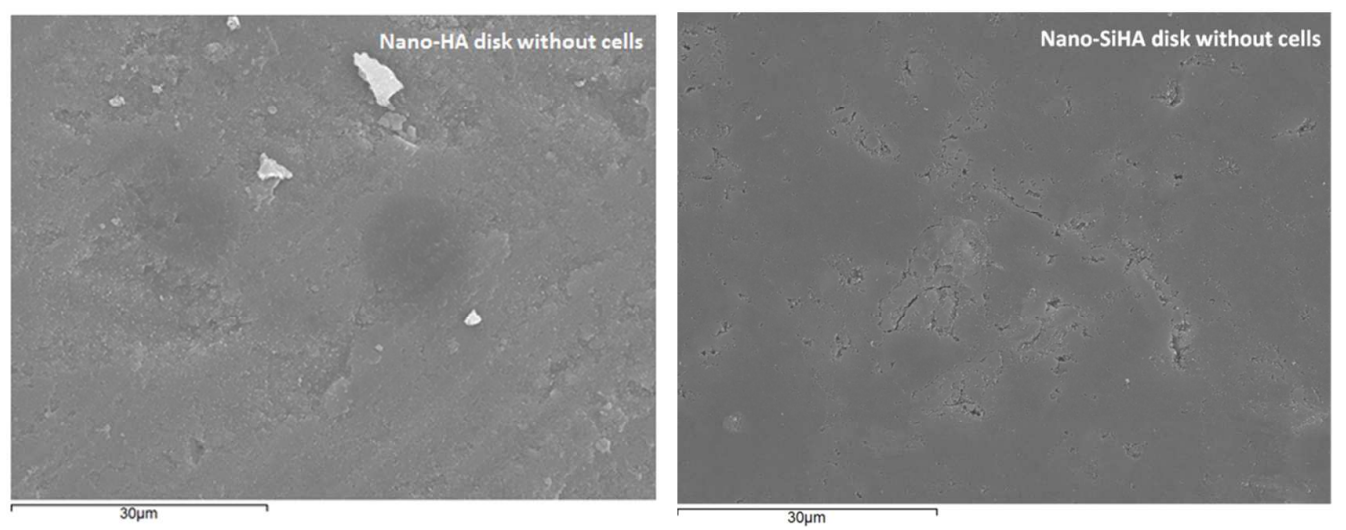

8. Characterizations of Nano-SiHA and Nano-HA (SEM, XPS) are suggested.

\section{Authors}

Following the reviewer's suggestions, SEM an EDX studies have been carried out. The results and discussion are included in this revised version. XPS experiments will be made in a future work.

\section{Referee: 2}

1. Materials and methods:

In 2.1, full name of TEOS $(\mathrm{Si}(\mathrm{CH} 3 \mathrm{CH} 2 \mathrm{O}) 4)$ should be presented in the first time when it appeared.

"The samples are treated at 700 degree......": what kind samples? Dried samples? Dried at which temperature?

"The HA and Si-HA grains thus obtained have a diameter ranging ......": does "the grain size" mean "the particle size"?

In 2.2, the authors used the Nano-HA and nano-siHA disks produced by uniaxial pressing on $300 \mathrm{mg}$ powders. Does the disc strong enough for manipulation during cell culture process?

In section 2.3, "Costar tanswells membranes were then placed into wells parallel controls were carried out in the absence of materials". How were the cells of control groups cultured? were they growing on the Costar Transwell membranes? During the culture period ( 7 days), was the medium refreshed.

\section{Authors}

Following the reviewers suggestions, the full name for TEOS "tetraethyl orthosilicate, $\mathrm{Si}\left(\mathrm{CH}_{3} \mathrm{CH}_{2} \mathrm{O}\right)_{4}$, (TEOS)" is presented in the first time it appears.

In order to clarify the processing of the different samples (powder and disks) the experimental section has been rewritten with the changes highlighted in the text. The temperature processing for all kind of samples (powder and disks) are clearly indicated in 
this new version. Regarding the mechanical strength of the disks, it must be said that they are strong enough to be manipulated during the cell culture process.

Concerning section 2.3, the text has been corrected because the results included in the present study correspond to RAW-264.7 cells which were cultured in direct contact with $1 \mathrm{mg} / \mathrm{ml}$ of either nano-HA or nano-SiHA for $24 \mathrm{~h}$. Thus, Costar Transwell membranes were not used for these assays. The cells of control groups were cultured in parallel in the absence of material at the same experimental conditions.

2. 3. Results and discussion: "To know the possible effects of these biomaterials on macrophage phenotypes, the ......, with high and low intracellular ROS content, was carried out in the samples" How was this experiment done? The author should add this information in the experimental section. Especially, how to control the ROS content in two RAW-264.7 cell populations?

\section{Authors}

2'-7'-Dichlorodihydrofluorescein diacetate (DCFH/DA) is one of the most widely used probes for directly measuring the intracellular content of reactive oxygen species (ROS). DCFH/DA is diffused into cells and is deacetylated by cellular esterases to non-fluorescent 2 ',7'-Dichlorodihydrofluorescin (DCFH), which is rapidly oxidized to highly fluorescent DCF by ROS. The detection of two RAW macrophage populations with high and low intracellular ROS is possible by flow cytometry which allows simultaneous multi-parameter analysis of single cells. This information has been included in the revised manuscript (sections 2.5 .2 and 3).

3. What are Figure 3 (and 4) A, B, C and D representing? Please indicate in their figure captions? it is better if the author can provide statistic results of each numbers of the multinucleated cells on the nano HA and SiHA samples!

\section{Authors}

More information is now provided in the captions of Figures 3 and 4 (figs 5 and 6, respectively in the revised version) in order to clarify the confocal images explaining that asterisks indicate the nuclei in the insets, thin arrows indicate the podosomes and thick arrows the F-actin ring which allows creation of the "sealing zone" for bone resorption. As suggested by the reviewer, a statistical analysis of the multinucleated cells on the nano-HA and nano-SiHA has been carried out obtaining values of $10 \%$ of multinucleated cells on both materials. However, in contact with nano-SiHA, these multinucleated cells contain two nuclei and the multinucleated cells on nano-HA disks contain four or five. These data have been included in the text of the revised manuscript.

4. In Figure 8 , cells in figure $8 \mathrm{~b}$ are more spread out than those in figure $8 \mathrm{~d}$, in addition, there are both round-shaped and spread-out cells on both samples (Figure 8a and c), which make it difficult to compare the thickness of the cells.

\section{Authors}

Since the Scanning Electron Microscopy images do not show clear differences between the podosomes of the cells attached on nano-HA and nano-SiHA, the conclusion for 
Figure 8 (fig 10 in the revised version) has been eliminated in the revised manuscript, as suggested by the reviewers 1 and 2.

5. Regarding the resorption cavity in Figure 9, how sure were the authors about the fact that the pits observed on the SEM pictures were resorption cavity? As the HAP is biodegradable, it is highly possible that some erosion pits formed under the influence of the culture medium during 21 days of incubation. Did the author set a control which is HAp discs without osteoclast-like cells incubated for 21 days in cell culture medium? And the authors are also suggested to provide the SEM pictures of the discs before cell culture. As the discs made by mechanical pressing without densification by sintering, the cavity is also possibly formed by the delamination of the "powder debris" from the discs after long-term immersion in liquid.

\section{Authors}

As we have explained above in point 7 of reviewer 1, the SEM images in figure 9 (fig 11 in revised version) correspond certainly to caves produced by the resorptive activity of osteoclasts cultured on nano-HA and nano-SiHA disks because the size of these caves are in the size range of cells and because these caves were not observed on disks without cells (before and after incubation in cell culture medium). The two images which are included above in point 7 of reviewer 1 correspond to nano-HA and nano-SiHA disks without cells and these samples did not show caves with size similar to cell size. These two images have not included in the revised manuscript to avoid an excess of figures. As suggested by the reviewer 1 in point 7, we have considered more caves to carry out the statistical analysis of the cave size obtaining values of $10 \pm 1.7 \mu \mathrm{m}$ (on nano-SiHA) and $32.5 \pm 9.7$ um (on nanoHA). The statistical significance of these values was ${ }^{* *} p<0.01$. These data have been included in the text of the revised manuscript.

Following the reviewer's suggestion, SEM studies and EDX spectroscopy have been included in the revised version (figures 1 and 2).

6. Both $\mathrm{HA}$ and $\mathrm{Si}-\mathrm{HA}$ are biodegradable, and also the incorporation of Si must influence the dissolution of $\mathrm{Ca}$ and $\mathrm{P}$ in the $\mathrm{Si}-\mathrm{HA}$ as the crystalline lattice was changed. Therefore, as the $\mathrm{Ca}$ and $P$ also potentially influence the activity of osteoclasts in a dose-dependent manner, together with the fact that the $\mathrm{Ca}$ and $\mathrm{P}$ released from the nano HA and SiHA are different, is it not scientifically accuracy to conclude the difference in the osteoclastic behaviours observed on the HA and SiHA discs were solely caused by Si ions. Have the authors looked at the ion release profiles of both discs? And how did the $\mathrm{Ca}$ and $\mathrm{P}$ ions influence the behaviours of osteoclasts seeded on their surfaces?

\section{Authors}

Since the hydroxyapatite bioactivity could produce the sequestration of calcium in the extracellular medium, and taking into account that the $\mathrm{Ca}^{2+}$ ion plays a crucial role in cell processes, $\mathrm{Ca}^{2+}$ levels were measured recently in the culture medium during previous studies with macrophages and both materials [M.C. Matesanz et al., Journal of Colloid and Interface Science 416 (2014) 59-66, new reference 46]. Previous results have shown a significant $\mathrm{Ca}^{2+}$ decrease in the culture medium produced by both nano-HA and nano-SiHA, more pronounced with nano-SiHA, in agreement with the higher bioactivity of this material [34]. The observed 
sequestration of extracellular calcium can be partially responsible of the lower proliferation of osteoclasts on nano-SiHA observed in the present study. These previous results concerning extracellular calcium have been commented in the revised manuscript and related with the significant lower cell growth on nano-SiHA than on nano-HA disks observed in the present study (Figure 7A in the new version).

Referee: 3

1. Authors should conduct more experiments to confirm that the $\mathrm{Si}$ ions are the major factor to contribute the decreased osteoclastogenesis. Therefore, authors should apply pure Si ions with different concentrations to interact with osteoclasts and further explore the osteoclastogenesis.

Authors

The biological effects of silicon on bone cells like osteoblasts and osteoclasts have already been studied by other authors [34,36, 45], demonstrating that silicon has a dual role in bone: it enhances osteoblasts proliferation and differentiation, whereas it causes an inhibition of osteoclast gene-expression, osteoclast formation and bone resorption in vitro [45]. Dose-dependent effects of Si on osteoclast development and resorption have been documented in vitro[34]. Nevertheless, it is still unclear whether these effects are directly caused by the silicon ions released by the Si-substituted calcium phophates. However, it is known that silicon ions affect calcium solubility [36], which in turn, has an influence on biological activity of osteoblasts and osteoclasts. As we have indicated above (point 6 of reviewer 2), previous results have shown a significant $\mathrm{Ca}^{2+}$ decrease in the culture medium produced by both nano-HA and nano-SiHA, more pronounced with nano-SiHA [46], in agreement with the higher bioactivity of this material [34]. The observed sequestration of extracellular calcium can be partially responsible of the lower proliferation of osteoclasts on nano-SiHA observed in the present study. To sum up, the role of silicon on osteoclastogenesis is clear enough so it makes no necessary to conduct more experiments to confirm the effect of Si ions. However, the authors thank the reviewer and will take into account the suggestions for future studies.

2. Rankle and OPG should be investigated for the osteoclastogenesis.

Authors

It is well known the importance of the RANKL/RANK/OPG system in the control of bone remodelling (Pivonka et al., Journal of Theoretical Biology, 2010; Boyce et al., Archives of Biochemistry and Biophysics, 2008; Wada et al, TRENDS in Molecular Medicine, 2006). The biological activity of osteoblasts and osteoclasts is closely coordinated, so the correct balance between both cell type activities is of extreme importance. In this sense, osteoblasts produce some molecules like RANKL and OPG in order to regulate osteoclasts function. For this reason, cocultive studies with osteoblasts and osteoclasts are currently being carried out 
which are closer to an in vivo situation. These results will be published in the near future. Nevertheless, authors thank the reviewer and will take into account his suggestions for future studies.

I do hope you will consider the reviewed manuscript suitable for publication.

Thanking you very much for your attention, I remain

Sincerely yours

Prof. M. Teresa Portolés

Departamento de Bioquímica y Biología Molecular I

Facultad de Ciencias Químicas

Universidad Complutense, 28040-Madrid, Spain

E-mail: portoles@quim.ucm.es 